\title{
Development and initial validation of the Psychological Need Frustration Scale for Physical Activity
}

\author{
Pak Kwong Chung ${ }^{\text {Corresp., } 1}$, Tao Zhong ${ }^{\text {Corresp., }}{ }^{2}$, Jing Dong Liu ${ }^{3}$, Chun Qing Zhang ${ }^{1}$, Ming Yu Claudia Wong ${ }^{1}$ \\ ${ }^{1}$ Department of Sport and Physical Education, Hong Kong Baptist University, Hong Kong, Hong Kong \\ 2 College of Sport and Health, Henan Normal University, Henan, China \\ 3 Department of Physical Education, Sun Yat-Sen University, Guangdong, China \\ Corresponding Authors: Pak Kwong Chung, Tao Zhong \\ Email address: pkchung@hkbu.edu.hk, tzhong_research@hotmail.com
}

Background: The frustration of basic psychological needs can be detrimental to people's health. To date, a scale developed specifically for measuring such perceived negative experiences, derived from a need thwarting environment in the physical activity context, is lacking. The present research attempted to develop and validate the Psychological Need Frustration Scale for Physical Activity (PNFS-PA) grounded in self-determination theory via multiple studies. Method: In Study 1, an item pool was created, and its face and content validity were established. In Study 2, the factor structure of the scale was demonstrated using exploratory structural equation modelling (ESEM). In Study 3, its factor structure was cross-validated. Also, the nomological validity, reliability and measurement invariance of the scale were established. Result: Taken together, the research suggests the newly developed PNFS-PA is valid and reliable and can be applied to assess psychological needs frustration experiences in the physical activity context. 


\section{Development and Initial Validation of the}

2 Psychological Need Frustration Scale for Physical

3 Activity

Pak-Kwong Chung ${ }^{*}$, Tao Zhong ${ }^{2}$, Jing-Dong Liu ${ }^{3}$, Chun-Qing Zhang ${ }^{1}$, Ming Yu Claudia Wong ${ }^{1}$

\section{Tao Zhong ${ }^{2}$}

${ }^{1}$ Department of Sport and Physical Education, Faculty of Social Sciences, Hong Kong Baptist University, Hong Kong, China

${ }^{2}$ College of Sport and Health, Henan Normal University, Henan, China

${ }^{3}$ Department of Physical Education, Sun Yat-Sen University, Guangdong, China

*Co-corresponding Author:

Pak-Kwong Chung ${ }^{1}$

Department of Sport and Physical Education, Faculty of Social Sciences, Hong Kong Baptist University, Hong Kong, China.

Email address: pkchung@hkbu.edu.hk

College of Sport and Health, Henan Normal University, Henan, China.

Email address: tzhong research@hotmail.com

\section{Abstract}

Background: The frustration of basic psychological needs can be detrimental to people's health.

To date, a scale developed specifically for measuring such perceived negative experiences, derived from a need thwarting environment in the physical activity context, is lacking. The present research attempted to develop and validate the Psychological Need Frustration Scale for Physical Activity (PNFS-PA) grounded in self-determination theory via multiple studies. Methods and Results: In Study 1, an item pool was created, and its face and content validity were checked and established. In Study 2, the factor structure of the scale was demonstrated using exploratory structural equation modelling (ESEM). In Study 3, its factor structure was cross-validated. Also, the nomological validity, reliability (internal consistency reliability and test-retest reliability) and measurement invariance of the scale were established. reliable and can be applied to assess psychological needs frustration experiences in the physical activity context.

Keywords: Self-determination theory, Basic psychological needs theory, Exploratory structural 


\section{Introduction}

Engaging in physical activity (PA) regularly is an effective way to maintain a healthy and fit body (Lee et al., 2012; Feeny et al., 2014; Humphreys, McLeod \& Ruseski, 2014). However, physical inactivity remains a major problem in global health (Pratt et al., 2014; Trost, Blair \& Khan, 2014). As such, facilitating PA among the general population is an important task in health and fitness promotion initiatives. In this sense, basic psychological needs theory (BPNT), as a sub-theory in self-determination theory (SDT; Ryan \& Deci, 2017), might be a useful framework to help understand PA behavior. According to BPNT, there are three innate, nonhierarchical and universal psychological needs, namely needs for autonomy, competence and relatedness (Ryan, 1995). Autonomy is defined as a sense of self-volition and self-governance over one's behavior. Competence refers to the perception that one can successfully achieve a challenging task. Relatedness is characterized as perceived positive and meaningful connections with others, and the feeling of belonging (Ryan \& Deci, 2017).

To date, a large number of studies have revealed that people with high need satisfaction likely experience self-determination for behavior (e.g. PA behavior), optimal functioning, personal growth and subjective well-being (Reeve \& Jang, 2006; Williams et al., 2009). Despite the relative plethora of research on needs satisfaction, only a few recent attempts have been made to explore the influence of need frustration. As advocated by Ryan and Deci (2017), not only the bright side (needs satisfaction) but also the dark side (needs frustration) of human experiences should be taken into account. Need frustration is referred to as perception of the basic psychological needs are being thwarted, which is undermining, alienating and pathogenic (Ryan \& Deci, 2017). Specifically, autonomy need frustration can occur in an environment characterized as controlling. Competence need frustration can take place when people are made to feel ineffective in an environment demeaning of their ability. Relatedness need frustration can happen in a cold and neglectful environment (Vansteenkiste, Niemiec \& Soenens, 2010). As a distinct psychological aspect, need frustration is not equivalent simply with the state of lacking basic psychological need satisfaction (Bartholomew et al., 2011). As demonstrated in previous empirical studies, lack of need satisfaction is not ideal for negative outcomes and maladaptation prediction (Adie, Duda \& Ntoumanis, 2012; Mack et al., 2012). Therefore, previous measures of basic psychological needs satisfaction are inappropriate to measure need frustration experiences, as their items only capture positive aspects of basic psychological needs. Developing measures with items that explicitly tap into the negative aspects of basic psychological needs (i.e. need frustration) is warranted.It is posited that negative consequence (e.g. fragmentation, maladaptation and ill-being) would be more salient when basic psychological needs frustration are directly measured (Bartholomew et al., 2011; Vansteenkiste \& Ryan, 2013).

In the context of PA, people could experience need frustration when engaging in PA in a social environment characterized as need thwarting ( $\mathrm{Ng}$ et al., 2013). Thwarting behavior from others (e.g. family members, friends, co-workers, classmates, PA instructors) could result in need frustration. For example, if a husband uses contingent rewards to motivate his wife to participate in PA, this may frustrate her basic psychological needs and make her feel pressured. To explore need frustration experiences in the PA specific context, a psychometrically sound measurement is desirable. However, currently, there is no such measurement available for researchers, which limits investigation in this domain. Although an endeavor has been made to modify a need frustration scale from a competitive sport context (Bartholomew et al., 2011; Martinent, GuilletDescas \& Moiret, 2015) to a PA context (Gunnell et al., 2013), such modification is somewhat problematic. For instance, the values of the CFI and TLI resided in an acceptable range (i.e. 
86 above .90), but the value of the RMSEA (.10) was not acceptable (i.e. below .08; Hu \& Bentler, 87 1999), indicating the model may not fit the data very well. Further, an inspection of the content 88 of the modified scale indicated that some modified items may not fit the PA context. For instance, the item "I feel inadequate because I am not given opportunities to fulfil my potential" in the competence need frustration factor and the item "I feel that other people are envious when I achieve success" in the relatedness need frustration factor is more pertinent to athletes in the context of a competitive sport rather than the PA context. PA behaviors of the general population are more health maintenance/enhancement oriented other than competition-oriented, and descriptions such as "fulfilling potential" and "achieving success" are not very relevant to the PA context. Taken together, it appears that the modified scale from competitive sport may not be an ideal instrument for measuring PA need frustration and there is an opportunity to expand and improve upon prior work in this area.

Besides, traditionally confirmatory factor analysis (CFA) was employed in validations studies of need frustration scales (Gunnell et al., 2013). However, it has been criticized for relying on a highly restrictive independent cluster model, where cross-loadings of items on unintended factors are forced to be zero (Asparouhov \& Muthén, 2009). Given the three basic psychological needs are distinct while inter-correlated, CFA approach might be inappropriate in analyzing the structure of their measurement. Also, a highly restrictive model in CFA would inflate the correlations of latent factors, which could fail to detect the genuine correlations between factors (Joshanloo, Bobowik \& Basabe, 2016). For instance, inflated factor correlations have been found in prior studies using CFA, where the correlations between autonomy need frustration and competence need frustration, between autonomy need frustration and relatedness need frustration, and competence need frustration and relatedness need frustration were $.96, .85$ and .95, respectively (Gunnell et al., 2013). To overcome the limitations from a statistical perspective, exploratory structural equation modelling (ESEM) has been advocated and gaining its popularity. ESEM allows for non-significant cross-loadings, which enables researchers to freely estimate cross-loadings and it has less restrictive assumptions (Marsh et al., 2014).

113 Moreover, it is an advance to traditional exploratory factor analysis (EFA), as it integrates the principles of the EFA into the framework of SEM, which allows for the examination of more complex models, such as measurement invariance models in validation studies. Therefore, ESSM could be adopted as a statistical approach in the present research.

The purpose of this research was to develop and validate the psychological need frustration scale for PA (PNFS-PA). Three studies were included to achieve the research purpose. In Study 1, the item pool of the PNFS-PA was produced, and the face and content validity of items were examined. In Study 2, the initial PNFS-PA produced in Study 1 was examined to explore scale structure through ESEM. In Study 3, the factor structure was cross-validated in an independent sample via ESEM. Additionally, nomological validity, reliabilities (Cronbach's

123 alpha, composite reliability and test-retest reliability) and measurement equivalence of the scale were examined.

125

\section{Methods and Results}

The purpose of this study was three-fold. First, it was to generate an item pool of the PNFS-PA, which was inputted from both the relevant measurements and qualitative interviews. 
130 Second, it aimed to assess the PNFS-PA's face validity through participants drawn from the

131

132

133

134

135

136

137

138

139

140

141

142

143

144

145

146

147

148

149

150

151

152

153

154

155

156

157

158

159

160

161

162

163

164

165

166

167

168

169

170

171

172

173

174

175 targeted population. Third, the PNFS-PA's content validity reflecting the extent to which an instrument measures the underlining theoretical construct was evaluated by specialists in the research field.

\section{Method \\ Participants}

Nineteen Chinese participants (age $=38.68 \pm 14.13$, age-range 20-64, nine males and ten females) were recruited and invited for interviews, through which their need frustration experiences under the PA context was explored. Inclusion criteria were: general Chinese adults in Hong Kong aged between 18 and 64. Exclusion criteria were: adults with major complaints or medical conditions that may interfere with PA engagement; athletes and students majored in $\mathrm{PE} /$ sport; and manual workers or people whose work requires a high PA level.

In addition, after the initial item pool for the PNFS-PA was formed, ten Chinese adults (age $=43.90 \pm 15.35$, age-range 21-64, five males and five females) were invited to assess its face validity. Recruitment criteria were the same. Moreover, three Chinese sport and exercise psychologists with expertise in SDT were invited to review the content validity of the items of the PNFS-PA.

\section{Procedure}

Prior to commencement, the study was approved by the Research Ethics Committee at Hong Kong Baptist University (HASC/16-17/0304). An initial item pool was sourced from two inputs. First, items from need frustration measurements in other related domains such as competitive sport (Bartholomew et al., 2011) and physical education (Liu \& Chung, 2015) were referred. Items were carefully reviewed to examine their applicability to the PA context. Those that could benefit the creation of the PNFS-PA's item pool were borrowed and adapted. Second, interviews on participants' need frustration experiences in the PA context were undertaken to supplement the PNFS-PA's item pool. Following a semi-structured interview guideline, participants were provided with lay definitions of the basic three psychological needs and asked by considering their (past and/or present) PA experiences, to discuss situations in which their feelings of autonomy, competence, and relatedness were undermined. Subsequently, the PNFSPA's item pool was presented to participants so as to check the face validity, readability, clarity and comprehensibility of items. Candidate items perceived as inapplicable/redundant by $70 \%$ or more of the participants were deleted.

The participants in study 1 were recruited using convenience sampling. They were recruited from several local communities (university campuses and public spaces such as squares and parks) in Hong Kong, via the distribution of invitation sheets. Interested participants consented and engaged in the study.

To assess the content validity of the PNFS-PA's pool of items, three Chinese specialists from universities in Hong Kong were contacted via email. They received their PhD training in (sport and exercise) psychology and had SDT-related publications in international peer-refereed journals. The three judges were provided with a definition of the psychological need frustration and were invited to review to what extent the items were applicable to the PA context. They rated individual items on a four-point Likert scale ( 1 = not applicable; 2 = somewhat applicable; 3 = quite applicable; $4=$ highly applicable) using their expertise. Subsequently, the content validity index (CVI) was calculated for every single item for further consideration (whether a certain item would be retained or deleted). The CVI of each item was computed by dividing the 
176 number of experts who gave a rating on either " 3 " or " 4 " by three, the total number of experts

177 involved.Consistent with previous research, a value of CVI $=1.00$ was considered excellent,

178 while a CVI's value of 0.67 was deemed acceptable. A CVI of 0.33 or less resulted in the

179 corresponding deletion of a given item (Polit \& Beck, 2006). CVI is an important approach to

180 evaluating content validity by quantifying the degree to which elements of an assessment

181 instrument are relevant to a targeted construct (Almanasreh, Moles \& Chen, 2019). Its use can be

182 seen in research developing psychological need frustration instrument for competitive sport

183 context (Bartholomew et al., 2011) and physical education context (Liu \& Chung, 2015). In

184 addition, suggestions concerning any possible ambiguity and revisions of candidate items were

185 also derived from the experts.

186 Of note, the term "physical activity" used in the research refers to any bodily movement

187 produced by skeletal muscles that require energy expenditure (Caspersen, Powell \& Christenson,

188 1985). To facilitate the term understanding by participants involved in the research, some

189 common forms of PA such as running, dancing, swimming, yoga and other recreational sports

190 (basketball, badminton, etc.) were provided. The term provides the context in which a person

191 may experience need frustration, such as from physical activity instructors, significant others and

192 peers who do not understand and appreciate PA-related decisions and perspectives.

193

194

195

196

197

198

199

\section{Results}

A total of 34 items (in Chinese) were initially generated for the PNFS-PA. During the face validity evaluation phase, 15 items that were classified as inapplicable or redundant with other items based on participants' feedback were deleted, resulting in 19 items. In addition, the relevance, comprehensibility and clarity of the remained items were checked by the participants. The items retained were successively reviewed by three SDT experts. Based on their feedback, three items (two items in competence need frustration factor and one item in relatedness need frustration factor) were rated as inapplicable, namely scored as "1" or " 2 " by two judges, with a value of CVI of 0.33 . Therefore, they were deleted which remained 16 items. Also, qualitative feedback regarding the further improvement of items was elicited, and minor revisions were made to enhance the quality of the scale's items. In summary, after following serial steps of PNFS-PA's item pool creation and refinement, an initial 16-item scale (six items for autonomy need frustration, four items for competence need frustration and six items for relatedness need frustration) was formed for subsequent studies.

\section{Study 2}

The purpose of Study 2 was to examine the factor composition of the initial scale via exploratory structural equation modelling (ESEM) using Mplus version 7.0. The examination was to: a) avoid misspecification of items in each underlying factor (e.g. ascertain item created for the competence need frustration loaded on the competence need frustration factor); $b$. maximize the convergent and discriminant validity of the scale.

\section{Method}

Participants and procedure

Participants were three hundred and thirty Chinese adults in Hong Kong. Their age ranged from 18 to $63(\mathrm{M}=33.85, \mathrm{SD}=15.12)$, with 141 males and 189 females.

Inclusion/exclusion criteria were the same as that of the last study. An invitation sheet containing 
222 the study information and an online survey QR code was created and distributed to university

223 students in Hong Kong, to invite them and people in their close social environment (e.g. relatives,

224 friends, etc. and cover the age range 18-64) to participate in the study. Interested participants

225 signed the informed consents online and engaged in the study. In the introduction section of the

226 online survey, the term "physical activity" was explained, as did in study 1 . This could help

227

228

229

230

231

232

233

234

235

236

237

238

239

240

241

242

243

244

245

246

247

248

249

250

251

252

253

254

255

256

257

258

259

260

261

262

263

264

265

266

267 participants better understand the context in which need frustration experience could take place. Participants were also clearly informed regarding the voluntary and anonymous nature of their participation at the beginning of the online survey. Research Ethics Committee at Hong Kong Baptist University approved the conduct of the study.

\section{Measures}

Demographic information. For basic demographic information, two items concerning participants' age and gender were asked in the survey battery.

Need frustration. The 16-item PNFS-PA generated from study 1 was adopted. Items are anchored along a seven-point Likert scale ranging from 1 (strongly disagree) to 7 (strongly agree).

\section{Data analysis}

ESEM was conducted to explore the structure of the PNFS-PA using Mplus Version 7.0 (Muthén \& Muthén, 2012). Oblique geomin rotation was used with an epsilon value of 0.5 and a robust maximum likelihood (MLR) estimation. Three factors were specified in the model for the autonomy, competence and relatedness need frustration, respectively. Given $\chi^{2}$ is sensitive to sample size, an array of indices including comparative fit index (CFI), Tucker-Lewis index (TLI), root mean square error of approximation (RMSEA), and standardized root mean square residual (SRMR) was used to evaluate the model fit (Hu \& Bentler, 1999). In line with previous research using ESEM (Marsh, Hau \& Grayson, 2005), CFI and TLI values $>0.90$, and RMSEA and SRMR values $<0.08$ are indicative of acceptable model fit, while CFI and TLI values $>0.95$, and RMSEA and SRMR values $<0.06$ are indicative of good model fit. When it comes to item retention/removal, the following criteria were employed: first, items with a large standardized factor loading (i.e. > .40) on unintended factor loading (e.g. autonomy need frustration item loaded highly on competence or relatedness need frustration factor) were removed; second, items with a high cross-loading (i.e. $>$.30) with another factor were removed; third, items with a standardized primary factor loading $<.40$ (which manifests item did not loaded on any factor) were removed (Matsunaga, 2010).

\section{Results}

The initial ESEM displayed an adequate model fit to the data, where $\chi^{2}(75)=178.334, p$ $<.001, \mathrm{CFI}=.961, \mathrm{TLI}=.938, \mathrm{RMSEA}(90 \% \mathrm{CI})=.065(.052, .077), \mathrm{SRMR}=.024$. However, an inspection of the standardized factor loadings based on aforementioned criteria revealed that one item in the autonomy need frustration factor and one item in the relatedness need frustration factor had a cross-loading problem, thus they were discarded and the second round of ESEM was implemented. The second round of ESEM resulted in an improved model fit, where $\chi^{2}(52)=$ $114.012, p<.001, \mathrm{CFI}=.973, \mathrm{TLI}=.952, \mathrm{RMSEA}(90 \% \mathrm{CI})=.060(.045, .075), \mathrm{SRMR}=.020$. The standardized factor loadings based on the aforementioned criteria were inspected and found no problem. Therefore, the factor structure of the scale was initially established. As for factor labelling, according to item content, factor 1, 2 and 3 were labelled as autonomy, competence 
284

285

286

287

288

289

290

291

292

293

294

295

296

297

298

299

300

301

302

303

304

305

306

307

308

309

310

311

312

313

and relatedness need frustration, respectively. Coefficients of Cronbach's alpha of the autonomy, competence and relatedness need frustration subscales were $.903, .881$, and 940 . The descriptive analysis result, standardized factor loadings of the scale's items and factor correlations are presented in Table 1. In summary, via the implementation of the ESEM, the factorial validity of the PNFS-PA was examined. Two items that showed poor discriminant validity were discarded, resulting in a scale with 14 items. The resultant scale would be administered to an independent sample in the next study to further investigate its validity and reliability.

\section{Study 3}

The purposes of Study 3 were to: cross-validate the factor composition of the PNFS-PA via ESEM using Mplus version 7.0; establish the nomological validity of the scale through correlation analysis between the PNFS-PA scale's factors and related constructs based on the premise of SDT (i.e. subjective vitality and negative affect), and examine the measurement invariance of the newly designed scale.

\section{Method \\ Participants and procedure}

As with the last two studies, participants were recruited in Hong Kong. Criteria for inclusion/exclusion were the same as study 1 and 2. Three hundred and twenty-two Chinese participants (age range 18-62, age $=37.44 \pm 15.21$ years, 158 males and 164 females) completed an online survey. In addition, an independent sample of 49 participants (age $=19.51 \pm 1.21$ years, age range 18-22, 21 males and 28 females) were invited to fill in the PNFS-PA twice (three week-interval between test and retest) to examine the scale's temporal stability.

The study procedure was the same as outlined in the last study. Informed consents from all participants were obtained online. Participants were clearly informed regarding the voluntary and anonymous nature of their participation at the beginning of the online survey. Ethical clearance for the present study was sought and received from the authors' local research ethics committee.

\section{Measures}

Demographic information. For basic demographic information, two items concerning participants' age and gender were asked in the survey battery.

Need frustration. The PNFS-PA established in Study 2 was adopted. It comprises 14 items (five items for the autonomy need frustration, four items for the competence need frustration and five items for the relatedness need frustration, respectively), anchored along a seven-point Likert scale, ranging from 1 (strongly disagree) to 7 (strongly agree).

Subjective well-being. The six-item Subjective Vitality Scale (SVS; Bostic, Rubio, \& Hood, 2000; Ryan \& Frederick, 1997) that measures respondents' perception of positive energy was used for nomological validity assessment. Responses are rated on a seven-point Likert scale ranging from 1 (strongly disagree) to 7 (strongly agree). The previous study has supported its application among the Chinese population (Liu \& Chung, 2015).

Negative affect. The five-item negative effect factor from the ten-item International Positive and Negative Affect Schedule Short Form (IPANAS-SF; Thompson, 2007) was used to measure participants' negative affect. It served as the assessment of the nomological validity of 
314 the PNFS-PA. Respondents were asked to respond to items anchored along a five-point Likert

315 scale ranging from 1 (never) to 5 (always). Previous research has supported its validity and

316 reliability among the Chinese population (Liu \& Chung, 2015).

317

318

319

320

321

322

323

324

325

326

327

328

329

330

331

332

333

334

335

336

337

338

339

340

341

342

343

344

345

346

347

348

349

350

351

352

353

354

355

356

357

358

\section{Data analysis}

The strategy for factorial validity examination was the same as that of the last study. ESEM was conducted to cross-validate the factor structure of the PNFS-PA using Mplus Version 7.0 (Muthén \& Muthén, 2012). With regard to the nomological validity assessment of the scale, based on the theoretical tenet of SDT (Vansteenkiste \& Ryan, 2013; Ryan \& Deci, 2017), it was predicted that need frustration would positively relate with negative affect, while negatively related with subjective well-being. As for the scale's reliability appraisal, once its structure was validated, internal consistency reliability assessment using Cronbach's alpha and composite reliability (Raykov, 1997) would be adopted. Additionally, the intra-class correlation and its 95\% CI obtained from a two-way random model (McGraw \& Wong, 1996) were adopted to assess three-week interval temporal stability of the scale.

Multi-group ESEM was used for measurement invariance testing across gender, age and independent samples. Samples from study 2 and 3 were used. To compare models and examine their invariance, since the $\chi^{2}$ difference test is dependent on sample size (Marsh, Balla \& McDonald, 1988), it was not used. Instead, we used multiple fit indices containing CFI, RMSEA and SRMR. Changes less than .010 for CFI, .015 for RMSEA and .030 for SRMR are the criteria for measurement invariance (Chen, 2007). Moreover, information criteria consisting of the Akaike information criteria (AIC), the Bayesian information criterion (BIC), and the sample size adjusted BIC (ABIC) were also used for comparing models. Lower values of the information criteria indicate a better model fit to the data.

\section{Results}

The cross-validated model revealed an adequate goodness-of-fit to the data, where $\chi^{2}(52)$ $=122.674, p<.001, \mathrm{CFI}=.969, \mathrm{TLI}=.947, \mathrm{RMSEA}=.065(.050, .080), \mathrm{SRMR}=.025$. Table 2 shows the descriptive analysis results, standardized factor loadings of items and the factor correlations. As to the result of nomological validity examination, as displayed in Table 3 , the correlations between scores of the autonomy, competence and relatedness need frustration subscales and the score of subjective vitality were in the expected negative direction, while the correlations between scores of the autonomy, competence and relatedness need frustration subscales and the score of negative affect were in the expected positive direction. Also, need frustration demonstrated a stronger correlation with the indicator of negative experiences than the indicator of positive experiences. The results confirmed the nomological validity of the newly developed scale.

The Cronbach's alpha coefficients of the three need frustration subscales were all above .800 (See Table 3 ), indicating the reliability of the newly designed scale was reasonable.

Furthermore, as for the temporal stability assessment of the scale, the intra-class correlation coefficients and their $95 \% \mathrm{CI}$ for autonomy, competence and relatedness need frustration were $.825(.690, .901), .804(.652, .890)$, and $.865(.761, .924)$, respectively. All were statistically significant at $p<.001$. The result showed the scale was stable over time. 
Multi-group ESEM analysis results are displayed in Table 4. Based on goodness-of-fit indices, both the independent models and invariance models showed sufficient fit to the data. When comparing the models constrained to varying degrees, changes in model fit indices (i.e. CFI, RMSEA and SRMR) were all smaller than suggested cutoff values indicative of measurement invariance. Furthermore, information criteria (i.e. AIC, BIC and ABIC) showed consistent values in different comparing models. The result supported the scale was invariant across gender (male vs female), age groups, and independent samples, which indicated the comparison of scores of the PNFS-PA across groups would be meaningful.

\section{Discussion}

Basic psychological need frustration is detrimental to people's health (Vansteenkiste \& Ryan, 2013), and can induce mal-adaptation and subjective ill-being (Adie, Duda \& Ntoumanis, 2012; Balaguer et al., 2012). Given its diminishing impact, researchers have taken action to tap into such perceived negative experiences in various contexts such as competitive sport (Bartholomew et al., 2011) and physical education (Van den Berghe et al., 2015). However, need frustration, derived from a need thwarting environment and taking place in the PA context, has been less explored. Among all obstacles, lack of a valid and reliable measure is an important one. Therefore, this research filled the gap by developing the PNFS-PA and examining its psychometric properties. Overall, the newly designed 14-item scale revealed satisfactory psychometric characteristics, indicating it can be a useful tool for future research in the PA specific context.

A series of analysis procedures were followed to develop and validate the PNFS-PA. First, an item pool of the scale was generated from two inputs, that is, items from relevant scales (Bartholomew et al., 2011; Liu \& Chung, 2015; Longo et al., 2016; Rocchi et al., 2017) and qualitative interviews. The combination of the two inputs is to maximize the content coverage of frustration of different basic psychological needs. Face validity of the items was examined by participants from the targeted population. Additionally, clarity, readability and comprehensibility of the items were checked. Content validity of the PNFS-PA was subsequently reviewed by experts in the SDT research filed. In the present research, the content validity index (CVI), the widely used index for scale evaluation as a quantitative approach (Polit \& Beck, 2006), was computed for item retention or deletion decision, resulting in an initial scale of the PNFS-PA.

The initial scale was administered to participants drawn from the targeted population for further analysis. As suggested in previous research, the ESEM approach was introduced to examine the factorial validity of the scale (Asparouhov \& Muthén, 2009; Marsh et al., 2009). Traditionally confirmatory factor analysis (CFA) was used in examining the factorial validity of a scale (Mueller, 1996). However, it has been criticized as relying on a highly restrictive independent cluster model. The model forces cross-loadings of items on unintended factors to zero, which overlooks the fact that the three factors in the scale are distinct yet related (Deci \& Ryan, 2014). To overcome such limitation, ESEM is suggested to use to better represent the multi-dimensional structure of a scale, which allows items to freely cross-load on other factors (Asparouhov \& Muthén, 2009). Therefore, we attempted to advance the literature by adopting a different statistical approach. The finalized 14-item scale demonstrated an adequate fit to the data via ESEM, supporting its factorial validity. Furthermore, the ESEM results from two independent samples (study 2 and 3) revealed that items loaded significantly higher in their intended factors rather than unintended factors, suggesting items in the newly developed scale explicitly measure a single need frustration, which is deemed an important item 
405

406

407

408

409

410

411

412

413

414

415

416

417

418

419

420

421

422

423

424

425

426

427

428

429

430

431

432

433

434

435

436

437

438

439

440

441

442

443

444

445

446

447

448

449

450 inclusion/exclusion criterion. In addition, the three factors' inter-correlations were better estimated in the ESEM, with a moderate correlation magnitude between three need frustration factors.

With regard to nomological validity of the scale, as expected, significant negative correlations between the three needs frustration and subjective vitality, and significantly positive correlations between the three needs frustration and negative affect were displayed. The findings substantiate SDT's argument and previous results (Bartholomew et al., 2011; Vansteenkiste \& Ryan, 2013; Liu \& Chung, 2015). The three needs frustration correlated more strongly with negative affect than subjective vitality, indicating it can be a better predictor for individuals' negative experiences under the PA context. Of note, in comparison with other contexts such as competitive sport (Bartholomew et al., 2011) and physical education (Liu \& Chung, 2015), the correlation magnitude between needs frustration and well/ill-being measurements in the PA context was relatively lower. It may be ascribed to the specific nature of the PA context, which involves a higher degree of freedom and more self-directed choice compared with other contexts such as competitive sport and physical education which are more compulsory. As such, it is possible that people may opt-out or relapse from PA participation to prevent their basic needs from being frustrated. Another probable explanation is that, for the individuals targeted in the current research (general Chinese adults), a large proportion of them are physically inactive. Hence, PA engagement appears to be a less significant component in their daily lives, and the possible negative experiences from the PA context may generate a less critical impact on perception of their overall subjective well/ill-being. Therefore, the relatively low association intensity observed was considered to be reasonable. Nonetheless, given the health benefits of PA engagement along with the adverse influence of need frustration that can repel people from PA participation, need frustration should be of causation.

As to the reliability of the scale, multiple indicators were introduced in the present research. That is Cronbach's alpha coefficient, composite reliability and test-retest reliability. Overall, the result suggests that the newly developed scale holds sufficient internal consistency reliability and temporal stability. Moreover, measurement invariance (weak, strong, and strict) of the scale was appraised across gender, age and independent samples. Weak, strong and strict measurement invariance requires factor loadings, factor mean (reflected by invariant intercepts) and residual variance to be equivalent across groups, which constitutes progressively constrained models (Meredith \& Teresi, 2006). Findings on the measurement invariance of the PNFS-PA suggest that scores derived from different groups are comparable.

It is worthy to note that need frustration, which is the interest of the current research, differs from need thwarting. Need frustration can be described as a perception of basic psychological needs are thwarted, hence it is a subjective experience (Bartholomew et al., 2011). Conversely, need thwarting is the act of thwarting people's basic psychological needs (Quested et al., 2018). Past studies sometimes use the two terms interchangeably. That is, they measured need frustration while referring it as need thwarting (Bartholomew et al., 2011). To avoid confusion, the name of our scale explicitly indicates that need frustration is the target of measurement. Plus, items in the PNFS-PA explicitly refer to feelings related to need thwarting behaviors, rather than need thwarting behaviors themselves. By doing so, the scale avoids a possible risk of mixing two related but distinct concepts in SDT.

The current research has several implications. First, the newly developed scale makes a measure of need frustration available, which could assist researchers in further exploring need frustration experiences in the context of PA. Second, from a theoretical perspective, it provides 
451

452

453

454

455

456

457

458

459

460

461

462

463

464

465

466

467

468

469

470

471

472

473

474

475

476

477

478

479

480

481

482

483

484

485

486

487

488

489

490

491

492

493

494

495

496

empirical support to the basic psychological need theory, namely needs for autonomy, competence and relatedness in a specific context (i.e., PA context). Third, it offers further insight into the motivational roots of maladjustment from an SDT approach. As the findings highlight a negative association between need frustration and negative affect, the practical implication is that it is important to tackle the negative psychological experiences in the PA context.

Though promising evidence on the psychometric properties of the need frustration scale is obtained, limitations should be acknowledged. First, samples in the present study were drawn via a convenience sampling strategy which may not be representative of the target population (Fogelman, 2002). In order to strengthen the generalizability of the findings, future validation studies should attempt to recruit participants via random sampling that can better represent the population. Also, we adopted samples from study 2 and 3 for the multi-group ESEM analysis. While the analysis results corroborated the invariance of the instrument, it would be a better strategy to recruit two new samples in study 3 for such an analysis. Second, only three experts were involved in the content validity appraisal stage. Despite they had expert knowledge germane to the present research, it is still recommended that a larger number of experts in different areas be included (Rubio et al., 2003). Third, while the face validity and content validity of the PNFS-PA were checked before formal administration, a subsequent pilot study could have been desirable. Such a pilot study could be useful in troubleshooting any potential unforeseen issues prior to large-scale questionnaire administration (Johanson \& Brooks, 2010). Fourth, regarding the nomological validity evaluation of the PNFS-PA, only subjective vitality and negative affect scales were employed. Despite the included constructs are suggested to be linked with need frustration and are important criteria for nomological validity assessment, other measures should also be taken into consideration. For instance, future research should consider entailing behavioral motivations of PA behavior for further validity assessment purpose. Within the framework of SDT, the frustration of the basic psychological needs is expected to exhibit a positive association with controlled behavioral motivation and a negative association with autonomous behavioral motivation (Ryan \& Deci, 2017). Moreover, some other alternative measures of maladaptation such as psychological distress should be included to further validate the newly developed scale in future studies.

\section{Conclusions}

In summary, although scale validation is an on-going process, the current research developed and initially validated the PNFS-PA, exhibiting its psychometric solidness. The scale can be useful for addressing need frustration in the PA specific context. Investigation of need frustration in PA should be of importance, as need frustration is detrimental experience individuals may have when engaging in PA behavior. It can cause negative outcomes such as negative affect, mal-adaptation and subjective ill-being and PA relapse. Therefore, PA intervention practice is informed to redress it. Additionally, individuals' important others (e.g. friends, family members, PA instructors) should be better informed with the adverse consequences of their conscious/unconscious need thwarting behavior in the PA context through educational and interventional campaigns. Thus, need frustration experiences can be better curbed. In all, this research contributes to the literature by providing a psychometric sound need frustration instrument for use in the PA context, and it is hoped that the availability of such a valid and reliable scale can facilitate and promote pertinent research in the future. 


\section{Acknowledgements}

498 Grant Disclosure

499 The research was funded by the Faculty Research Grant (FRG) of Hong Kong Baptist University

500 (FRG1/16-17/039)

\section{Competing Interests}

502 The authors declare that they have no competing interests.

\section{Author Contributions}

504 PKC, TZ, and JDL were involved in the design of the study protocol and the data acquisition. PKC and 505 TZ conducted all analyses and wrote the first draft. PKC, TZ, JDL, and CQZ contributed to the

506 interpretation of the results. MYCW contributed to the language editing and formatting of the manuscript.

507 All authors critically reviewed the manuscript and approved the final version.

508

509

510

511

512

513

514

\section{Human Ethics}

The current study involves human participants and the research protocol had been approved by the Committee of Use of Human and Animal Subjects in Teaching and Research (Project Code: HASC/1617/0304) at the Hong Kong Baptist University. Informed consents from all participants were obtained online.

\section{References}

Adie JW, Duda JL, Ntoumanis N. 2012. Perceived coach-autonomy support, basic need satisfaction and the well-and ill-being of elite youth soccer players: A longitudinal investigation. Psychology of Sport and Exercise 13:51-59. DOI: 10.1016/j.psychsport.2011.07.008.

Almanasreh E, Moles R, Chen TF. 2019. Evaluation of methods used for estimating content validity. Research in Social and Administrative Pharmacy 15:214-221. DOI: 10.1016/j.sapharm.2018.03.066.

Asparouhov T, Muthén B. 2009. Exploratory structural equation modeling. Structural Equation Modeling: A Multidisciplinary Journal 16:397-438. DOI: 10.1080/10705510903008204.

Balaguer I, González L, Fabra P, Castillo I, Mercé J, Duda JL. 2012. Coaches' interpersonal style, basic psychological needs and the well-and ill-being of young soccer players: A longitudinal analysis. Journal of Sports Sciences 30:1619-1629. DOI: 10.1080/02640414.2012.731517.

Bartholomew K, Ntoumanis N, Ryan RM, Thøgersen-Ntoumani C. 2011. Psychological need thwarting in the sport context: Assessing the darker side of athletic experience. Journal of Sport and Exercise Psychology 33:75-102. DOI: 10.1123/jsep.33.1.75.

Van den Berghe L, Cardon G, Tallir I, Kirk D, Haerens L. 2015. Dynamics of need-supportive and need-thwarting teaching behavior: the bidirectional relationship with student engagement and disengagement in the beginning of a lesson. Physical Education and Sport Pedagogy:1-18. DOI: 10.1080/17408989.2015.1115008.

Caspersen CJ, Powell KE, Christenson GM. 1985. Physical activity, exercise, and physical fitness: definitions and distinctions for health-related research. Public health reports 
538

539

540

541

542

543

544

545

546

547

548

549

550

551

552

553

554

555

556

557

558

559

560

561

562

563

564

565

566

567

568

569

570

571

572

573

574

575

576

577

578

579

580

581

582

583

100:126-131.

Chen FF. 2007. Sensitivity of goodness of fit indexes to lack of measurement invariance. Structural equation modeling 14:464-504. DOI: 10.1080/10705510701301834.

Deci EL, Ryan RM. 2014. Autonomy and need satisfaction in close relationships: Relationships Motivation Theory. In: Human motivation and interpersonal relationships. Springer, 53-73. Feeny D, Garner R, Bernier J, Thompson A, McFarland BH, Huguet N, Kaplan MS, Ross NA, Blanchard CM. 2014. Physical Activity Matters: Associations Among Body Mass Index, Physical Activity and Health-Related Quality of Life Trajectories Over 10 Years. Journal of physical activity \& health 11:1265-1275. DOI: 10.1123/jpah.2012-0268.

Fogelman K. 2002. Research Methods in Educational Leadership and Management. In: Coleman M, Briggs A eds. Research methods in educational leadership and management. Sage, 93107.

Gunnell KE, Crocker PREE, Wilson PM, Mack DE, Zumbo BD. 2013. Psychological need satisfaction and thwarting: A test of Basic Psychological Needs Theory in physical activity contexts. Psychology of Sport and Exercise 14:599-607. DOI: 10.1016/j.psychsport.2013.03.007.

$\mathrm{Hu}$ L, Bentler PM. 1999. Cutoff criteria for fit indexes in covariance structure analysis: Conventional criteria versus new alternatives. Structural equation modeling: $a$ multidisciplinary journal 6:1-55. DOI: 10.1080/10705519909540118.

Humphreys BR, McLeod L, Ruseski JE. 2014. Physical activity and health outcomes: evidence from Canada. Health Economics 23:33-54. DOI: 10.1002/hec.2900.

Johanson GA, Brooks GP. 2010. Initial scale development: sample size for pilot studies. Educational and psychological measurement 70:394-400. DOI: 10.1177/0013164409355692.

Joshanloo M, Bobowik M, Basabe N. 2016. Factor structure of mental well-being: Contributions of exploratory structural equation modeling. Personality and Individual Differences 102:107-110. DOI: 10.1016/j.paid.2016.06.060.

Lee I-M, Shiroma EJ, Lobelo F, Puska P, Blair SN, Katzmarzyk PT, Group LPASW. 2012. Effect of physical inactivity on major non-communicable diseases worldwide: an analysis of burden of disease and life expectancy. The lancet 380:219-229. DOI: 10.1016/S01406736(12)61031-9.

Liu JD, Chung PK. 2015. Development and Initial Validation of the Chinese Version of Psychological Needs Thwarting Scale in Physical Education. Journal of Teaching in Physical Education 34:402 - 423. DOI: 10.1123/jtpe.2014-0053.

Longo Y, Gunz A, Curtis GJ, Farsides T. 2016. Measuring need satisfaction and frustration in educational and work contexts: The Need Satisfaction and Frustration Scale (NSFS). Journal of Happiness Studies 17:295-317. DOI: 10.1007/s10902-014-9595-3.

Mack DE, Wilson PM, Gunnell KE, Gilchrist JD, Kowalski KC, Crocker PRE. 2012. Health-Enhancing Physical Activity: Associations with Markers of Well-Being. Applied Psychology: Health and Well-Being 4:127-150. DOI: 10.1111/j.1758-0854.2012.01065.x.

Marsh HW, Balla JR, McDonald RP. 1988. Goodness-of-fit indexes in confirmatory factor analysis: The effect of sample size. Psychological bulletin 103:391-410. DOI: 10.1037/0033-2909.103.3.391.

Marsh HW, Hau K-T, Grayson D. 2005. Goodness of fit in structural equation models. In: Maydeu-Olivares A, McArdle JJ eds. Contemporary psychometrics. Mahwah: Lawrence Erlbaum Associates Publishers, 275-340. 
584

585

586

587

588

589

590

591

592

593

594

595

596

597

598

599

600

601

602

603

604

605

606

607

608

609

610

611

612

613

614

615

616

617

618

619

620

621

622

623

624

625

626

627

628

629

Marsh HW, Morin AJS, Parker PD, Kaur G. 2014. Exploratory structural equation modeling: An integration of the best features of exploratory and confirmatory factor analysis. Annual review of clinical psychology 10:85-110. DOI: 10.1146/annurev-clinpsy-032813-153700.

Marsh HW, Muthén B, Asparouhov T, Lüdtke O, Robitzsch A, Morin AJS, Trautwein U. 2009. Exploratory structural equation modeling, integrating CFA and EFA: Application to students' evaluations of university teaching. Structural Equation Modeling: A Multidisciplinary Journal 16:439-476. DOI: 10.1080/10705510903008220.

Martinent G, Guillet-Descas E, Moiret S. 2015. Reliability and validity evidence for the French Psychological Need Thwarting Scale (PNTS) scores: Significance of a distinction between thwarting and satisfaction of basic psychological needs. Psychology of Sport and Exercise 20:29-39. DOI: 10.1016/j.psychsport.2015.04.005.

Matsunaga M. 2010. How to Factor-Analyze Your Data Right: Do's, Don'ts, and How-To's. International journal of psychological research 3:97-110.

McGraw KO, Wong SP. 1996. Forming inferences about some intraclass correlation coefficients. Psychological methods 1:30-46. DOI: 10.1037/1082-989X.1.4.390.

Meredith W, Teresi JA. 2006. An essay on measurement and factorial invariance. Medical care 44:S69-S77.

Mueller RO. 1996. Confirmatory factor analysis. In: Basic Principles of Structural Equation Modeling. Springer, 62-128.

Muthén LK, Muthén BO. 2012. Mplus Version 7 user's guide.

Ng JYY, Ntoumanis N, Thøgersen-Ntoumani C, Stott K, Hindle L. 2013. Predicting psychological needs and well-being of individuals engaging in weight management: The role of important others. Applied Psychology: Health and Well-Being 5:291-310. DOI: 10.1111/aphw.12011.

Polit DF, Beck CT. 2006. The content validity index: are you sure you know what's being reported? Critique and recommendations. Research in nursing \& health 29:489-497. DOI: 10.1002/nur.20147.

Pratt M, Norris J, Lobelo F, Roux L, Wang G. 2014. The cost of physical inactivity: moving into the 21 st century. British journal of sports medicine 48:171-173. DOI: $10.1136 /$ bjsports2012-091810.

Quested E, Ntoumanis N, Stenling A, Thogersen-Ntoumani C, Hancox JE. 2018. The NeedRelevant Instructor Behaviors Scale: Development and Initial Validation. Journal of Sport and Exercise Psychology 40:259-268. DOI: 10.1123/jsep.2018-0043.

Raykov T. 1997. Estimation of composite reliability for congeneric measures. Applied Psychological Measurement 21:173-184. DOI: 10.1177/01466216970212006.

Reeve J, Jang H. 2006. What teachers say and do to support students' autonomy during a learning activity. Journal of educational psychology 98:209. DOI: 10.1037/00220663.98.1.209.

Rocchi M, Pelletier L, Cheung S, Baxter D, Beaudry S. 2017. Assessing need-supportive and need-thwarting interpersonal behaviours: The Interpersonal Behaviours Questionnaire (IBQ). Personality and Individual Differences 104:423-433. DOI: 10.1016/j.paid.2016.08.034.

Rubio DM, Berg-Weger M, Tebb SS, Lee ES, Rauch S. 2003. Objectifying content validity: Conducting a content validity study in social work research. Social work research 27:94104. DOI: $10.1093 / \mathrm{swr} / 27.2 .94$.

Ryan RM. 1995. Psychological needs and the facilitation of integrative processes. Journal of 
630

631

632

633

634

635

636

637

638

639

640

641

642

643

644

645

646

647

648

personality 63:397-427. DOI: 10.1111/j.1467-6494.1995.tb00501.x.

Ryan RM, Deci EL. 2017. Self-determination theory: Basic psychological needs in motivation, development, and wellness. New York: Guilford Publications.

Trost SG, Blair SN, Khan KM. 2014. Physical inactivity remains the greatest public health problem of the 21 st century: evidence, improved methods and solutions using the ' 7 investments that work'as a framework. British journal of sports medicine 48:169-170. DOI: 10.1136/bjsports-2013-093372.

Vansteenkiste M, Niemiec CP, Soenens B. 2010. The development of the five mini-theories of self-determination theory: An historical overview, emerging trends, and future directions. In: Urdan T, Karabenick S eds. The Decade Ahead: Theoretical Perspectives on Motivation and Achievement (Advances in motivation and achievement). Emerald Publishing, 105-166.

Vansteenkiste M, Ryan RM. 2013. On psychological growth and vulnerability: Basic psychological need satisfaction and need frustration as a unifying principle. Journal of Psychotherapy Integration 23:263-280. DOI: 10.1037/a0032359.

Williams GC, Niemiec CP, Patrick H, Ryan RM, Deci EL. 2009. The importance of supporting autonomy and perceived competence in facilitating long-term tobacco abstinence. Annals of Behavioral Medicine 37:315-324. DOI: 10.1007/s12160-009-9090-y. 
650 Table 1.

651 Item Content, Descriptive Analysis, Factor Loadings and Factor Correlations in Study 2 (N $652=330)$

\begin{tabular}{llllllll}
\hline Item Content & $\begin{array}{l}\text { Mea } \\
n\end{array}$ & SD & SK & KU & A & CO & RE \\
& & & U & & \\
\hline
\end{tabular}

(Autonomy) When engaging in physical activity, at times you feel:

Restricted from making choice

Forced to follow decisions made for you

Other people make their demand without providing rationale

Other people use excessive personal control

Forced to do things that you don't want to

$\begin{array}{lllllll}3.48 & 1.55 & .24 & - & .73 & .03 & .03 \\ 5 & 8 & 2 & .64 & 9 & 6 & 8\end{array}$

$\begin{array}{lllllll}3.28 & 1.57 & .27 & - & .84 & - & .03 \\ 2 & 2 & 3 & .79 & 1 & .00 & 3\end{array}$

$\begin{array}{lllllll}3.19 & 1.57 & .44 & - & .75 & .15 & .03 \\ 4 & 3 & 1 & .48 & 4 & 5 & 9\end{array}$

$\begin{array}{lllllll}3.03 & 1.47 & .51 & - & .74 & .10 & .14 \\ 9 & 8 & 7 & .32 & 3 & 9 & 5\end{array}$

$\begin{array}{lllllll}2.97 & 1.55 & .56 & - & .56 & .20 & .21 \\ 9 & 4 & 8 & .50 & 8 & 2 & 5\end{array}$

(Competence) When engaging in physical activity, at times:

You are made to feel powerless in some situations

You feel incompetent because of things you are told

You doubt if you can achieve improvement because of comments you receive

You doubt your ability to overcome challenges because of comments you receive

$$
\begin{array}{lllllll}
4.19 & 1.63 & - & - & .09 & .66 & - \\
1 & 5 & .19 & .74 & 3 & 2 & .00 \\
& & 7 & 3 & & & 6 \\
3.92 & 1.58 & - & - & .10 & .75 & .06 \\
4 & 2 & .13 & .79 & 5 & 0 & 9
\end{array}
$$$$
\begin{array}{lllllll}
4.10 & 1.55 & - & - & .03 & .82 & .08 \\
0 & 3 & .20 & .68 & 4 & 1 & 5
\end{array}
$$$$
\begin{array}{lllllll}
3.87 & 1.54 & - & - & .03 & .76 & .13 \\
0 & 3 & 5 & .73 & 2 & 6 & 8
\end{array}
$$

(Relatedness) When engaging in physical activity, at times you feel:

You are rejected by those around you

Other people overlook you on purpose

$\begin{array}{lllllll}2.81 & 1.55 & .55 & - & .11 & .15 & .76 \\ 8 & 5 & 0 & 50 & 3 & 1 & 4\end{array}$

Other people say bad words about you

$\begin{array}{lllllll}2.72 & 1.45 & .56 & - & .10 & .08 & .76 \\ 4 & 6 & 0 & 3 & 0 & 8 & 4\end{array}$

$\begin{array}{lllllll}2.60 & 1.48 & .75 & - & .04 & .06 & .83\end{array}$




$\begin{array}{lllllll}0 & 5 & 4 & .24 & 8 & 5 & 5 \\ 7 & & & \end{array}$

Other people do not listen to you

Other people are reluctant to offer help

$\begin{array}{lllllll}2.85 & 1.47 & .51 & - & .07 & .17 & .75 \\ 2 & 1 & 2 & .59 & 1 & 5 & 5\end{array}$

\begin{tabular}{|c|c|c|c|c|c|c|c|c|c|}
\hline Oth & are rell & r help & 266 & 143 & 64 & & 11 & 11 & 76 \\
\hline & $\mathrm{CO}$ & $\mathrm{RE}$ & & & & & & & \\
\hline AU & $.346^{* * *}$ & $.352^{* * *}$ & & & & & & & \\
\hline $\mathrm{CO}$ & & $.410^{* * *}$ & & & & & & & \\
\hline
\end{tabular}

653 Note. SD, Standard deviation; SK, Skewness; KU, Kurtosis. AU, autonomy need frustration, CO, 654 competence need frustration; RE, relatedness need frustration. ${ }^{* * *} p<.001$.

655

656

657

658

659

660

661

662

663

664

665

666

Table 2.

$668 \mathbf{3}(\mathbf{N}=\mathbf{3 2 2})$

Item Content

$\begin{array}{lllllll}\text { Mea } & \text { SD } & \text { SK } & \text { KU } & \text { A } & \text { CO } & \text { RE }\end{array}$

$\mathrm{n}$

$\mathrm{U}$

(Autonomy) When engaging in physical activity, at times you feel:

Restricted from making choice

Forced to follow decisions made for you

$\begin{array}{lllllll}3.67 & 1.63 & .13 & - & .70 & .17 & - \\ 7 & 1 & 6 & .90 & 1 & 1 & .03 \\ & & & 8 & & & 7\end{array}$

Forced to follow decisions made for you

Other people make their demand without providing rationale

$\begin{array}{lllllll}3.42 & 1.61 & .19 & - & .72 & .17 & .08 \\ 9 & 1 & 9 & 73 & 7 & 0 & 5\end{array}$

Other people use excessive personal control

Forced to do things that you don't want to

$\begin{array}{lllllll}3.32 & 1.57 & .30 & - & .73 & .08 & .05 \\ 0 & 1 & 9 & 0 & 5 & 0 & 5\end{array}$

\begin{tabular}{lllllll}
3.11 & 1.58 & .51 & .47 & .76 & .08 & .17 \\
5 & 3 & 1 & 5 & 1 & 7 & 2 \\
3.11 & 1.61 & .45 & - & .70 & .13 & .20 \\
8 & 3 & 7 & .67 & 2 & 1 & 8 \\
\hline
\end{tabular}


(Competence) When engaging in physical activity, at times:

You are made to feel powerless in some situations

You feel incompetent because of things you are told

$\begin{array}{lllllll}4.16 & 1.55 & .20 & .70 & .09 & .42 & .10 \\ 5 & 7 & 2 & 0 & 5 & 7 & 5\end{array}$

You doubt if you can achieve improvement because of comments you receive

You doubt your ability to overcome challenges because of comments you receive

(Relatedness) When engaging in physical activity, at times you feel:

You are rejected by those around you

Other people overlook you on purpose

$\begin{array}{lllllll}4.01 & 1.52 & .10 & .62 & .09 & .64 & .07 \\ 6 & 5 & 6 & 4 & 8 & 2 & 3 \\ & & - & - & & & - \\ 4.00 & 1.55 & .17 & .63 & .03 & .90 & .00 \\ 6 & 1 & 7 & 3 & 5 & 1 & 5 \\ & & - & - & & & \\ 3.80 & 1.48 & .01 & .70 & .08 & .78 & .07 \\ 1 & 2 & 2 & 1 & 0 & 1 & 6\end{array}$

Other people say bad words about you

Other people do not listen to you

Other people are reluctant to offer help

$$
\begin{array}{lllllll}
2.81 & 1.54 & .65 & .30 & .08 & .09 & .80 \\
4 & 2 & 9 & 3 & 9 & 0 & 9
\end{array}
$$

$\mathrm{CO} \quad \mathrm{RE}$

\begin{tabular}{lll}
$\mathrm{AU}$ & $.429^{* * *}$ & $.401^{* * *}$ \\
$\mathrm{CO}$ & $.333^{* * *}$ \\
\hline
\end{tabular}


679 Cronbach's alpha and Correlations for Nomological Validity Examination in Study 3 ( $\mathbf{N}=$ 680 322)

\begin{tabular}{lll}
\hline & Subjective vitality $(\alpha=.915)$ & Negative affect $(\alpha=.792)$ \\
\hline $\begin{array}{l}\text { Autonomy need frustration } \\
(\alpha=.919)\end{array}$ & -.105 & $.207^{* * *}$ \\
$\begin{array}{l}\text { Competence need frustration } \\
(\alpha=.840)\end{array}$ & $-.136^{*}$ & $.182^{* *}$ \\
$\begin{array}{l}\text { Relatedness need frustration } \\
(\alpha=.938)\end{array}$ & $-.141^{*}$ & $.291^{* * *}$ \\
\hline
\end{tabular}

681 Note. ${ }^{*} p<.05,{ }^{* *} p<.01,{ }^{* * *} p<.001$.

682

683

684

685

686

687 
688

689

Table 4. Goodness-of-fit Indices of Models for Invariance Examination in Study 3 ( $\mathbf{N}=\mathbf{6 5 2})$

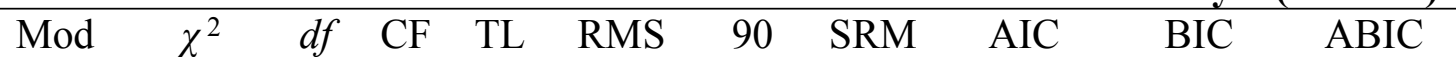
el $\quad$ I $\quad$ I $\quad$ EA $\quad \% \quad r$

CI

\begin{tabular}{|c|c|c|c|c|c|c|c|c|c|c|c|}
\hline \multirow[t]{15}{*}{ Gender } & Male & 106.0 & 52 & .97 & .95 & .059 & {$[.04$} & .021 & 12376.3 & 12624.2 & 12411.8 \\
\hline & $\begin{array}{l}(\mathrm{N}= \\
299)\end{array}$ & 81 & & 6 & 9 & & $\begin{array}{c}3, \\
.075\end{array}$ & & 67 & 97 & 14 \\
\hline & Fema & 145.9 & 52 & .95 & .92 & .072 & {$[.05$} & .024 & 14771.4 & 15030.5 & 14817.9 \\
\hline & le & 79 & & 9 & 7 & & 8 & & 97 & 50 & 99 \\
\hline & $(\mathrm{N}=$ & & & & & & .085 & & & & \\
\hline & 353) & & & & & & ] & & & & \\
\hline & M1 & 251.2 & 10 & .96 & .94 & .066 & {$[.05$} & .023 & 27147.8 & 27748.1 & 27322.7 \\
\hline & & 51 & 4 & 8 & 3 & & $\begin{array}{c}6, \\
.076\end{array}$ & & 64 & 90 & 41 \\
\hline & M2 & 293.5 & 13 & .96 & .95 & .059 & {$[.05$} & .033 & 27134.1 & 27586.6 & 27265.9 \\
\hline & & 46 & 7 & 6 & 4 & & $\begin{array}{c}0 \\
.069\end{array}$ & & 23 & 07 & 33 \\
\hline & M3 & 315.0 & 15 & .96 & .95 & .058 & {$[.04$} & .040 & 27124.4 & 27514.2 & 27238.0 \\
\hline & & 46 & 1 & 4 & 7 & & $\begin{array}{c}9 \\
.067\end{array}$ & & 80 & 44 & 20 \\
\hline & M4 & 3176 & 16 & 96 & 96 & 053 & ] & 043 & 271198 & 274468 & 272151 \\
\hline & & 05 & 5 & 6 & 3 & & 4 & & 38 & 81 & 07 \\
\hline & & & & & & & .062 & & & & \\
\hline \multirow[t]{9}{*}{ Age } & G1 & 117.2 & 52 & .97 & .95 & .062 & {$[.04$} & .021 & 13664.6 & 13918.3 & 13705.8 \\
\hline & $\begin{array}{l}(\mathrm{N}= \\
326)\end{array}$ & 89 & & 2 & 1 & & $\begin{array}{c}7, \\
.077\end{array}$ & & 22 & 44 & 24 \\
\hline & $\mathrm{G} 2$ & 134.1 & 52 & .96 & .93 & .070 & {$[.05$} & .024 & 13468.4 & 13722.1 & 13509.6 \\
\hline & $\begin{array}{l}(\mathrm{N}= \\
326)\end{array}$ & 55 & & 4 & 7 & & $\begin{array}{c}5, \\
.084\end{array}$ & & 46 & 68 & 49 \\
\hline & M1 & 251.7 & 10 & .96 & .94 & .066 & {$[.05$} & .022 & 27133.0 & 27733.3 & 27307.9 \\
\hline & & 40 & 4 & 8 & 4 & & $\begin{array}{c}6, \\
.076\end{array}$ & & 68 & 94 & 45 \\
\hline & M2 & 308.9 & 13 & .96 & .95 & .062 & {$[.05$} & .036 & 27136.2 & 27588.7 & 27268.0 \\
\hline & & 19 & 7 & 3 & 1 & & $\begin{array}{c}3, \\
.071\end{array}$ & & 15 & 00 & 25 \\
\hline & M3 & 323.1 & 15 & .96 & .95 & .059 & {$[.05$} & .035 & 27117.0 & 27506.7 & 27230.5 \\
\hline
\end{tabular}




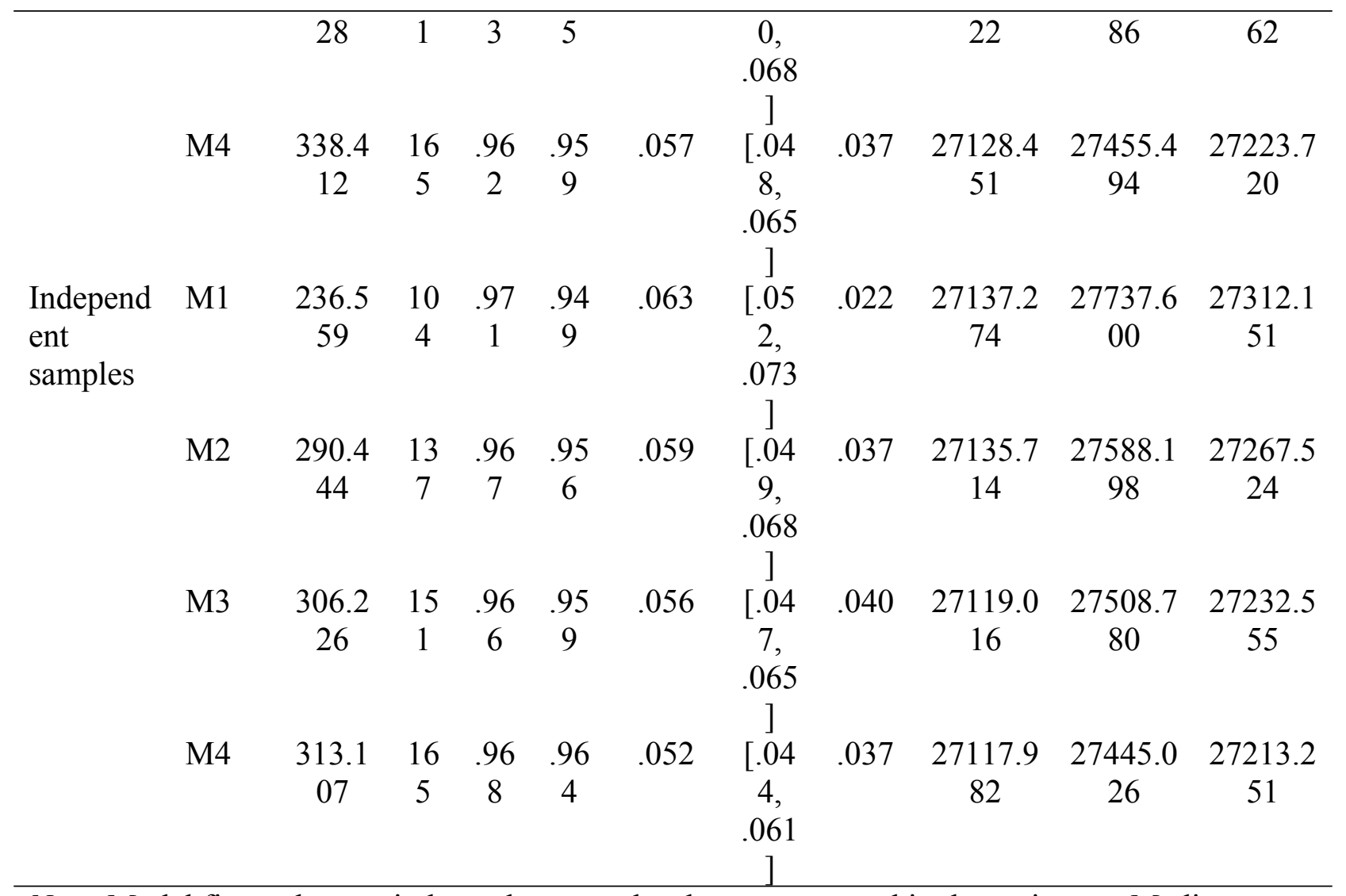

690

691

692

693
Note. Model fits to the two independent samples data are reported in the main text. Median age $=$ 37.50 of the participants was used for group division (G1 and G2). M1, configural invariance; M2, metric invariance (weak invariance); M3, scalar invariance (strong invariance); M4, item uniqueness invariance (strict invariance) 
696

697

698 


\section{Table 1 (on next page)}

Item Content, Descriptive Analysis, Factor Loadings and Factor Correlations, Goodness of fit 
2 Table 1.

3 Item Content, Descriptive Analysis, Factor Loadings and Factor Correlations in Study $2(\mathbf{N}=330)$

\begin{tabular}{|c|c|c|c|c|c|c|c|}
\hline Item Content & $\begin{array}{l}\text { Mea } \\
\mathrm{n}\end{array}$ & SD & SK & KU & AU & $\mathrm{CO}$ & $\mathrm{RE}$ \\
\hline \multicolumn{8}{|l|}{ (Autonomy) When engaging in physical activity, at times you feel: } \\
\hline Restricted from making choice & 3.485 & $\begin{array}{l}1.55 \\
8\end{array}$ & .242 & $\begin{array}{l}- \\
.642\end{array}$ & $\begin{array}{l}.73 \\
9\end{array}$ & .036 & .038 \\
\hline Forced to follow decisions made for you & 3.282 & $\begin{array}{l}1.57 \\
2\end{array}$ & .273 & $\begin{array}{l}- \\
.794\end{array}$ & $\begin{array}{l}.84 \\
1\end{array}$ & $\begin{array}{l}- \\
.001\end{array}$ & .033 \\
\hline Other people make their demand without providing rationale & 3.194 & $\begin{array}{l}1.57 \\
3\end{array}$ & .441 & $\begin{array}{l}- \\
.481\end{array}$ & $\begin{array}{l}.75 \\
4\end{array}$ & .155 & .039 \\
\hline Other people use excessive personal control & 3.039 & $\begin{array}{l}1.47 \\
8\end{array}$ & .517 & $\begin{array}{l}- \\
.323\end{array}$ & $\begin{array}{l}.74 \\
3\end{array}$ & .109 & .145 \\
\hline Forced to do things that you don't want to & 2.979 & $\begin{array}{l}1.55 \\
4\end{array}$ & .568 & $\begin{array}{l}- \\
.507\end{array}$ & $\begin{array}{l}.56 \\
8\end{array}$ & .202 & .215 \\
\hline \multicolumn{8}{|l|}{ (Competence) When engaging in physical activity, at times: } \\
\hline You are made to feel powerless in some situations & 4.191 & $\begin{array}{l}1.63 \\
5\end{array}$ & $\begin{array}{l}- \\
.197\end{array}$ & $\begin{array}{l}- \\
.743\end{array}$ & $\begin{array}{l}.09 \\
3\end{array}$ & .662 & $\begin{array}{l}- \\
.006\end{array}$ \\
\hline You feel incompetent because of things you are told & 3.924 & $\begin{array}{l}1.58 \\
2\end{array}$ & $\begin{array}{l}- \\
.139\end{array}$ & $\begin{array}{l}- \\
.791\end{array}$ & $\begin{array}{l}.10 \\
5\end{array}$ & .750 & .069 \\
\hline You doubt if you can achieve improvement because of comments you receive & 4.100 & $\begin{array}{l}1.55 \\
3\end{array}$ & $\begin{array}{l}- \\
.207\end{array}$ & $\begin{array}{l}- \\
.686\end{array}$ & $\begin{array}{l}.03 \\
4\end{array}$ & .821 & .085 \\
\hline $\begin{array}{l}\text { You doubt your ability to overcome challenges because of comments you } \\
\text { receive }\end{array}$ & 3.870 & $\begin{array}{l}1.54 \\
3\end{array}$ & .005 & .736 & $\begin{array}{l}.03 \\
2\end{array}$ & .766 & .138 \\
\hline
\end{tabular}




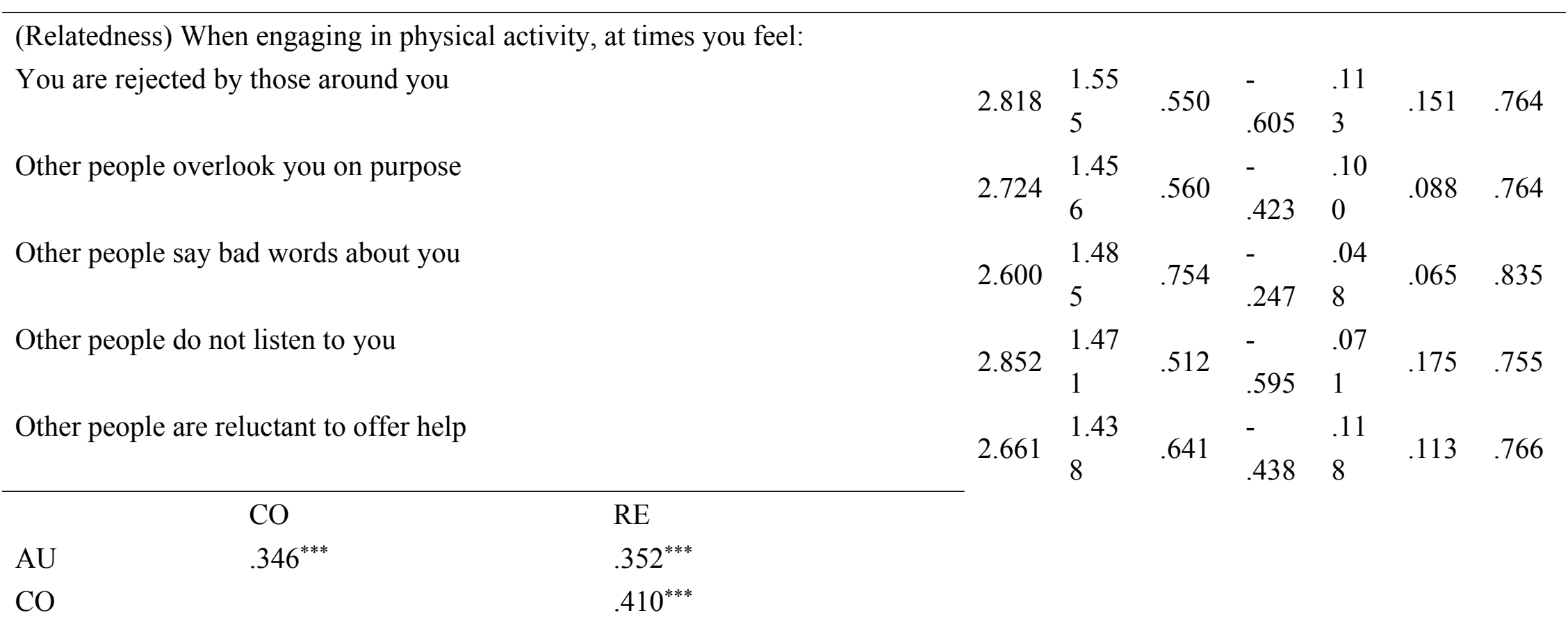

4 Note. SD, Standard deviation; SK, Skewness; KU, Kurtosis. AU, autonomy need frustration, CO, competence need frustration; RE, 5 relatedness need frustration. ${ }^{* * *} p<.001$. 


\section{Table 2 (on next page)}

Item Content, Descriptive Analysis, Factor Loadings and Factor Correlations, Goodness of fit 
1 Table 2.

2 Item Content, Descriptive Analysis and Factor Loadings and Factor Correlations in Study $3(\mathbf{N}=322)$

\begin{tabular}{|c|c|c|c|c|c|c|c|}
\hline Item Content & Mean & $\mathrm{SD}$ & SK & $\mathrm{KU}$ & $\mathrm{AU}$ & $\mathrm{CO}$ & $\mathrm{RE}$ \\
\hline \multicolumn{8}{|l|}{ (Autonomy) When engaging in physical activity, at times you feel: } \\
\hline Restricted from making choice & 3.677 & 1.631 & .136 & -.908 & .701 & .171 & -.037 \\
\hline Forced to follow decisions made for you & 3.429 & 1.611 & .199 & -.737 & .727 & .170 & .085 \\
\hline Other people make their demand without providing rationale & 3.320 & 1.571 & .309 & -.600 & .735 & .080 & .055 \\
\hline Other people use excessive personal control & 3.115 & 1.583 & .511 & -.475 & .761 & .087 & .172 \\
\hline Forced to do things that you don't want to & 3.118 & 1.613 & .457 & -.672 & .702 & .131 & .208 \\
\hline \multicolumn{8}{|l|}{ (Competence) When engaging in physical activity, at times: } \\
\hline You are made to feel powerless in some situations & 4.165 & 1.557 & -.202 & -.700 & .095 & .427 & .105 \\
\hline You feel incompetent because of things you are told & 4.016 & 1.525 & -.106 & -.624 & .098 & 642 & .073 \\
\hline You doubt if you can achieve improvement because of comments you receive & 4.006 & 1.551 & -.177 & -.633 & .035 & .901 & -.005 \\
\hline $\begin{array}{l}\text { You doubt your ability to overcome challenges because of comments you receive } \\
\text { (Relatedness) When engaging in physical activity, at times you feel: }\end{array}$ & 3.801 & 1.482 & -.012 & -.701 & .080 & .781 & .076 \\
\hline You are rejected by those around you & 2.814 & 1.542 & .659 & -.303 & .089 & .090 & .809 \\
\hline Other people overlook you on purpose & 2.835 & 1.571 & .658 & -.417 & .060 & .123 & .834 \\
\hline Other people say bad words about you & 2.689 & 1.505 & .744 & -.083 & .144 & .037 & .786 \\
\hline Other people do not listen to you & 2.953 & 1.527 & .518 & -.577 & .100 & .139 & .773 \\
\hline Other people are reluctant to offer help & 2.727 & 1.466 & .816 & .223 & .142 & .081 & .691 \\
\hline $\mathrm{CO}$ & & & & & & & \\
\hline $.401^{* * *}$ & & & & & & & \\
\hline $.333^{* * *}$ & & & & & & & \\
\hline
\end{tabular}

3 Note. SD, Standard deviation; SK, Skewness; KU, Kurtosis. AU, autonomy need frustration, CO, competence need frustration; RE, 4 relatedness need frustration. ${ }^{* * *} p<.001$. 


\section{Table 3 (on next page)}

Item Content, Descriptive Analysis, Factor Loadings and Factor Correlations, Goodness of fit 
1 Table 3.

2 Cronbach's alpha and Correlations for Nomological Validity Examination in Study $3(\mathbf{N}=\mathbf{3 2 2})$

\begin{tabular}{lll}
\hline & Subjective vitality $(\alpha=.915)$ & Negative affect $(\alpha=.792)$ \\
\hline $\begin{array}{l}\text { Autonomy need frustration } \\
(\alpha=.919)\end{array}$ & -.105 & $.207^{* * *}$ \\
$\begin{array}{l}\text { Competence need frustration } \\
(\alpha=.840)\end{array}$ & $-.136^{*}$ & $.182^{* *}$ \\
$\begin{array}{l}\text { Relatedness need frustration } \\
(\alpha=.938)\end{array}$ & $-.141^{*}$ & $.291^{* * *}$
\end{tabular}

Note. ${ }^{*} p<.05,{ }^{* *} p<.01,{ }^{* * *} p<.001$.

4

5

6

7

8

9

10 


\section{Table 4 (on next page)}

Item Content, Descriptive Analysis, Factor Loadings and Factor Correlations, Goodness of fit 
1 Table 4. Goodness-of-fit Indices of Models for Invariance Examination in Study 3 ( $\mathbf{N}=\mathbf{6 5 2})$

\begin{tabular}{|c|c|c|c|c|c|c|c|c|c|c|c|}
\hline & Model & $\chi^{2}$ & $d f$ & CFI & TLI & RMSEA & $90 \% \mathrm{CI}$ & SRMR & AIC & $\mathrm{BIC}$ & ABIC \\
\hline \multirow[t]{6}{*}{ Gender } & $\begin{array}{l}\text { Male } \\
(\mathrm{N}=299)\end{array}$ & 106.081 & 52 & .976 & .959 & .059 & $\begin{array}{l}{[.043,} \\
.075]\end{array}$ & .021 & 12376.367 & 12624.297 & 12411.814 \\
\hline & $\begin{array}{l}\text { Female } \\
(\mathrm{N}=353)\end{array}$ & 145.979 & 52 & .959 & .927 & .072 & $\begin{array}{l}{[.058,} \\
.085]\end{array}$ & .024 & 14771.497 & 15030.550 & 14817.999 \\
\hline & M1 & 251.251 & 104 & .968 & .943 & .066 & $\begin{array}{l}{[.056,} \\
.076]\end{array}$ & .023 & 27147.864 & 27748.190 & 27322.741 \\
\hline & M2 & 293.546 & 137 & .966 & .954 & .059 & $\begin{array}{l}{[.050,} \\
.069]\end{array}$ & .033 & 27134.123 & 27586.607 & 27265.933 \\
\hline & M3 & 315.046 & 151 & .964 & .957 & .058 & $\begin{array}{l}{[.049,} \\
.067]\end{array}$ & .040 & 27124.480 & 27514.244 & 27238.020 \\
\hline & M4 & 317.605 & 165 & .966 & .963 & .053 & $\begin{array}{l}{[.044,} \\
.062]\end{array}$ & .043 & 27119.838 & 27446.881 & 27215.107 \\
\hline \multirow[t]{6}{*}{ Age } & $\begin{array}{l}\text { G1 } \\
326)\end{array} \quad(\mathrm{N}=$ & 117.289 & 52 & .972 & .951 & .062 & $\begin{array}{l}{[.047,} \\
.077]\end{array}$ & .021 & 13664.622 & 13918.344 & 13705.824 \\
\hline & $\begin{array}{l}\mathrm{G} 2 \\
326)\end{array} \quad(\mathrm{N}=$ & 134.155 & 52 & .964 & .937 & .070 & $\begin{array}{l}{[.055,} \\
.084]\end{array}$ & .024 & 13468.446 & 13722.168 & 13509.649 \\
\hline & M1 & 251.740 & 104 & .968 & .944 & .066 & $\begin{array}{l}{[.056,} \\
.076]\end{array}$ & .022 & 27133.068 & 27733.394 & 27307.945 \\
\hline & M2 & 308.919 & 137 & .963 & .951 & .062 & $\begin{array}{l}{[.053,} \\
.071]\end{array}$ & .036 & 27136.215 & 27588.700 & 27268.025 \\
\hline & M3 & 323.128 & 151 & .963 & .955 & .059 & $\begin{array}{l}{[.050,} \\
.068]\end{array}$ & .035 & 27117.022 & 27506.786 & 27230.562 \\
\hline & M4 & 338.412 & 165 & .962 & .959 & .057 & $\begin{array}{l}{[.048,} \\
.065]\end{array}$ & .037 & 27128.451 & 27455.494 & 27223.720 \\
\hline \multirow[t]{4}{*}{$\begin{array}{l}\text { Independent } \\
\text { samples }\end{array}$} & M1 & 236.559 & 104 & .971 & .949 & .063 & $\begin{array}{l}{[.052,} \\
.073]\end{array}$ & .022 & 27137.274 & 27737.600 & 27312.151 \\
\hline & M2 & 290.444 & 137 & .967 & .956 & .059 & $\begin{array}{l}{[.049,} \\
.068]\end{array}$ & .037 & 27135.714 & 27588.198 & 27267.524 \\
\hline & M3 & 306.226 & 151 & .966 & .959 & .056 & $\begin{array}{l}{[.047,} \\
.065]\end{array}$ & .040 & 27119.016 & 27508.780 & 27232.555 \\
\hline & M4 & 313.107 & 165 & .968 & .964 & .052 & {$[.044$} & .037 & 27117.982 & 27445.026 & 27213.251 \\
\hline
\end{tabular}


2 Note. Model fits to the two independent samples data are reported in the main text. Median age $=37.50$ of the participants was used 3 for group division (G1 and G2). M1, configural invariance; M2, metric invariance (weak invariance); M3, scalar invariance (strong 4 invariance); M4, item uniqueness invariance (strict invariance). 
